\title{
La heterotopía en la obra de Edgardo Rodríguez Juliá
}

\author{
Jaime L. M artell-Morales
}

Universidad de Puerto Rico - M ayagüez, Puerto Rico

jmartell@uprm.edu

\section{RESU MEN}

El artículo plantea la tendencia de las obras del escritor puertorriqueño Edgardo Rodríguez Juliá al diálogo transgresivo con el discurso culturalista de interpretación nacional. Particularmente se examina la desarticulación de ciertos tópicos e imágenes que se emplearon para describir la nación y lo nacional. Entre estos, se examina la transgresión de la visión arcádica del pai saje nacional característica de buena parte de la literatura puertorriqueña desde el romanticismo. Plantea que el autor emplea el concepto de heterotopía de $\mathrm{M}$ ichel Foucault como una forma al terna de conceptualizar la nación y la cultura nacional, y de considerar el texto literario.

Palabras claves Arcadia, heterotopía, transgresión, cultura nacional, interpretación nacional.

\section{ABST RACT}

This article states the tendency in Edgardo Rodríguez Juliá's writings towards a transgressive dial ogue with the culturalistic discourse of national interpretation. It particularly examines the dismantling of certain topics and images which were used to describe the nation and the national thing. Among them, it studies the transgression of the national landscape's arcadic vision, which characterizes a great deal of Puerto R ican literature since Romanticism. It proposes that the author uses M ichel Foucault's concept of heterotopia as an alternative way to conceptualize nation and national culture, as well as the literary text.

Keywords Arcadia, heterotopia, transgression, cultural nacional ism, national interpretation.

Recibido: 29-03-2004. Aceptado: 25-06-2005. 
$Y$ resumo todas las anteriores sutilezas asegurando que el hombre no busca la historia de sus antiguos en los verdes prados o bellos lagos que provocan suma delectación en presente sino en las ruinosas ciudade rario de la vanidad de los hombres, depósito y guardián del sufrimiento de culpables e inocentes.

(La renuncia del héroe Baltasar, 51)

C STAS palabras son pronunciadas por Baltasar M ontañez, personaje princi- pal de la primera novela del escritor Edgardo Rodríguez Juliá, La renuncia del héroe Baltasar. La novela es una de sus tres obras ficcionales que versan sobre la gestación de la identidad cultural puertorriqueña durantee siglo XVIII. La cita, convocando el topos central de la imagen tradicional de la Arcadia, el locus amoenus, remite a los discursos literarios e historiográficos que caracterizaron una época precedente a la generación del escritor. La imagen de la nación como lugar ameno fue uno de los ejes centrales de la ensayística culturalista que se propuso definir la identidad puertorriqueña, y narrar la historia de su formación, haciendo de la imagen arcádica de la naturaleza uno de los emblemas característicos del imaginario histórico y social².

Las palabras del personaje, enunciadas como máxima o sentencia respecto al carácter pragmático de la historiografía, adquieren en el contexto de la obra un matiz visionario. La historia narrada en La renuncia del héroe Baltasar se encuadra dentro de una serie de conferencias que dicta el atenésta ficticio Alejandro C adal so, durante la década del 30, fecha que remite a la época histórica cuando los discursos cultural istas se institucionalizan como versiones oficiales de la historia puertorriqueña. La transformación de una ideología cultural en memoria colectiva, asentada sobre un model o de convivencia armónica identi-

${ }^{1}$ Las otras dos son: La noche oscura del niño Avilés (Río Piedras: H uracán, 1984) y El camino de Yyaloide (Venezuela: Grijalbo, 1994). Estas dos forman parte de una trilogía que el autor anunciara para la época de publicación de la primera.

${ }^{2}$ La imagen de la Arcadia configura el mundo de evocación que los letrados fabularon como respuesta a las tensiones suscitadas por los cambios sociales y económicos ocurridos en Puerto Rico desde comienzos de siglo. La emigración del campo a la ciudad, impulsada por los cambios económicos así como por la profesionalización, que logra integrar la sociedad rural al mundo urbano, determina la reactivación literaria del tópico que opone aldea/ciudad como compensación de lo rural ante el caos y las presiones de la vida citadina. D urante la Generación del 30, la actualización del tópico, aunque ofrece variaciones evidentes, y aun se muestra como crítica a la imagen idílica del paisaje característica del Romanticismo y el M odernismo, sigue constituyendo una formulación que intenta convocar un viejo orden. Para una discusión detallada de este aspecto ver la tesis doctoral de M aría Elena RodríguezCastro, particularmente el primer capítulo, "La fábrica de la ficción. El país", La "escritura de Io nacional" y "los intelectuales puertorriqueños" (Princeton U niversity, 1988). Para una discusión sucinta remitimos a su artículo "Las casas del porvenir: nación y narración en el ensayo puertorriqueño" (ver bibliografía). 
ficado con la hacienda cafetalera decimonónica, como reacción a una realidad cada vez más urbana e industrializada, llega a su más coherente formulación durante la $\mathrm{G}$ eneración del 30 . Insularismo, obra que se ofrece como "ensayos de interpretación puertorriqueña", de Antonio S. Pedreira, se convierte en el texto institucionalizador de esta interpretación cultural. El texto provee un modo de narrar la nación codificado como un sistema de tópicos, imágenes y estrategias narrativas, los cuales, según M aría E. Rodríguez-C astro, "resistieron la repetición y el desgaste de sus contenidos ideológicos excediendo las fronteras del marco letrado y alojándose permanentemente en el imaginario puertorriqueño" (1993, 35). Baltasar M ontañez, situado dos siglos antes de estas conferencias, anuncia una realidad que no se concretizará sino hasta después de la generación del ateneísta. Adelantándose en el tiempo, el personaje revela un hecho histórico que se producirá durante la época contemporánea al autor de la novela. Es precisamente cuando se publica la obra, coincidente con la llamada G eneración del 70, que la impugnación a los discursos culturalistas es más grave. Tanto la memoria cultural institucionalizada, como las imágenes que la conformaron y el prestigio de que antes gozaba comienzan a cuestionarse. La obra de Edgardo Rodríguez Juliá en este contexto es una de las instancias literarias más críticas y a la vez polémicas, en lo que se refiere a la discusión de la tradición y la historia cultural puertorriqueña, así como a la posición que se toma frente a ellas. Su obra, que ha sido objeto de una diversidad de juicios e interpretaciones, se enfila con las nuevas versiones y prácticas literarias que se distancian de las anteriores ofreciendo nuevos modos de ver y contar la realidad.

La crítica literaria y la historiografía recientes han examinado el trasfondo ideológico, así como la latencia y función de un continente imaginario, en los discursos de la tradición culturalista puertorriqueña en su diligencia por construir una memoria cultural ${ }^{3}$. La transmutación de la ideología cultural letrada en memoria colectiva alcanza su mayor concreción durante la década de los treinta como resultado de agudos conflictos sociales y políticos. La invasión del capital extranjero y las condiciones desventajosas de los antiguos hacendados urgían del letrado una intervención más activa en la estabilización nacional. Ante el desastre inminente los letrados intentan, mediante la escritura, ordenar la nación narrándole una historia; a la vez que proponían un proyecto.

Frente a la modernización y la fuerza atrayente que ejerció el espacio ciudada-

${ }^{3}$ Críticos puertorriqueños contemporáneos han emprendido la apreciable empresa de describir el proceso de constitución de la ideología culturalista en memoria cultural, así como de voces impugnadoras de ella. Los trabajos de Arcadio Díaz Q uiñones y de M aría Elena Rodríguez-C astro son particularmente importantes. Sus trabajos están muy presentes en estas reflexiones (ver bibliografía). 
no sobre los descendientes de la antigua élite cultural, el letrado responde idealizando el mundo rural, que para él signaba la vieja armonía familiar y nacional. En la evocación letrada la representación de una imagen idílica de la vida campe sina se opone a la imagen infernal de la ciudad. El viejo tópico que opone aldea/ ciudad se había reactivado en la obra literaria de algunos poetas modernistas, como Luis Lloréns Torres, como compensación de lo rural ante el caos y las presiones de la vida citadina (Rodríguez-C astro 1988, 58). La visión del mundo campesino como respuesta a las presiones del mundo citadino lleva a la idealización de la realidad vivida. En su poema "Tristeza jíbara", la pintura del mundo campesino como remanso de paz, donde el alma está en armonía con la naturaleza, dista mucho de la realidad social en el agro puertorriqueño (Fernández Valledor 1993, 150).

La imagen de la nación como formulación arcádica tuvo varios estadios diferenciables pero no irreconciliables. El mismo Pedreira establece sus diferencias al criticar la visión de la naturaleza en Gautier Benítez, figura central del Romanticismo puertorriqueño. En "Alarde y expresión", tercer ensayo de Insularismo, insiste en la visión genérica del paisaje en Gautier, cuyas descripciones carecen de verdad y muestran que el poeta "no sabía recoger el espíritu del paisaje y reproducirlo objetivamente en su poesía" ${ }^{4}$ D e Lloréns, a quien llama "nuestro poeta criollo", menciona su valor como exponente dela tendencia que él precisamente valora y proclama, el criollismo; sin embargo, critica la "jibarada literaria" que carece delargo alcance y propone un criollismo de ideas antialdeanas (69). Pedreira y los treintistas, aún distanciándose de la visión idílica del paisaje y el mundo campesino, siguen modelando su visión de la nación de acuerdo a un conjunto de normas y valores tradicionales atribuidos al agro, tras lo cual persiste la idealización del mundo campesino en oposición a lo urbano (Cf. Rodríguez-Castro 1993, 45).

Edgardo Rodríguez Juliá, dentro de las líneas de disensión que caracterizarán a su generación, Ileva a cabo en su obra literaria, narrativa y ensayística, una evaluación y crítica del imaginario social en todos sus niveles y dimensiones expresivas. Como intelectual asume una posición distanciada pero comprensiva, tanto de la tradición como de las tendencias alternativas a ella. Su segunda novela, La nocheoscura del niño Avilés, por ejemplo, explora en un plano imaginativo la historia cultural de Puerto Rico. La interacción de los diversos planos narrativos muestra, a partir de los dos topos centrales que los estructuran, la U topía y la Arcadia, las variadas versiones culturales que se desarrollaron en

\footnotetext{
${ }^{4}$ Cito de la edición de Concha M eléndez, 0 bras de Antonio S. Pedreira, tomo I: 63 (ver bibliografía).
} 
Puerto Rico ${ }^{5}$. La novela, de complicada trama, se ofrece como una suerte de pseudohistoria acerca de una rebelión de esclavos que durante el siglo XVIII, bajo el mando de su caudillo 0 batal, se apoderan de la ciudad de San Juan, bastión militar del régimen español, tras derrotar las fuerzas defensoras acaudiIladas por el obispo Larra. Antes de que ocurra esteincidente, la obra comienza con el relato del naufragio y rescate de un niño en un canastillo, a quien se le bautiza con el nombre de su salvador, Juan Avilés. Tras este suceso se generaliza entre el pueblo la creencia de que el N iño Avilés es una especie de mesías dotado con poderes sobrenaturales, por lo que se le comienza a rendir culto. Avilés luego pasa a ser custodiado por el obispo Larra. A partir de entonces, la trama va a girar en torno a la rebelión de esclavos, la toma de San Juan por éstos, la muerte de Larra, el éxodo de los criollos y la campaña del obispo Trespalacios para retomar la capital. Los hechos que se suceden son narrados por diversos cronistas, en cuyas crónicas se cuentan los innumerables proyectos visionarios y utópicos que producen muchos de los personajes principales de la novela: O batal y su nueva Torre de Babel; Trespalacios y la Ciudad de Dios; las ciudades aéreas que describe un narrador anónimo; la Arcadia criolla simbolizada por PepeD íaz, y la N ueva Venecia, cuya fundación habrá de ser descrita en una novela subsiguiente. Uno de los temas centrales de esta novela podría ser el sentido de carencia que caracteriza a estas formulaciones, marcadas por un sentimiento de desarraigo entonado con un hondo deseo de realización, que en última instancia las identifica en lugar de diferenciarlas ${ }^{6}$. Esta recurrencia literaria al tópico tradicional de la arcadia como formulación utópica la discute Richard Cody en su libro T he L andscape of the M ind, en el que explica la natu-

${ }^{5}$ Compartimos la interpretación de la novela como alegoría acerca de la historia de la cultura puertorriqueña de Aníbal González-Irrizarry. D e acuerdo al crítico, la novela ofrece una especie de catálogo alegórico de las distintas concepciones de la cultura insular formuladas durante el presente siglo. Puntualiza que las utopías que la novela baraja "no son sino versiones alegóricas de las ideas expresadas en varias obras clásicas de interpretación social y cultural de Puerto Rico producidas durante la década del treinta..." (1986: 587). En un artículo más reciente emparenta la novela con la tendencia de la novela hispanoamericana actual que recurre a la utilización de la al egoría figural para parodiar la ficción narrativa anterior que interpretaba el pasado colonial como prefiguración de la realidad presente (ver bibliografía).

${ }^{6}$ Respondiendo a una pregunta de Julio 0 rtega respecto al parentesco de La noche con las llamadas "novelas de nuestra historicidad", que ponen en crisis la historia misma, sus registros y códigos, el autor comenta:

N uestra historicidad implica un adentramiento en ese mal llamado "encuentro" de utopías anheladas y pasados destruidos, de grandes imágenes empobrecidas por la humillación de la memoria y la explotación del cuerpo. Se trata de una colisión, o encuentro catastrófico, de fuertes cosmogonías como la europea, la indoamericana, la africana (Julio O rtega, Reapropiaciones, 156). 
raleza de la Arcadia como proyección del deseo, y la imposibilidad de su realización:

But Arcadia is only a projection of the mind, a desire, a longing for peace. Arcadia is a dream never fully realized and at most an invaded dream because the individual cannot divorce himself from the conflicts of human existence (27).

El arquetipo de la Arcadia como proyección del deseo y la nostalgia de la armonía y quietud frente a los conflictos de la existencia humana se generaliza durante la época renacentista7. En la literatura ascética del poeta español Fray Luis de León, por ejemplo, el tema horaciano del beatusille, el elogio de la vida rústica, solitaria, aparece como rechazo de la vida de la ciudad. En "La vida retirada" la experiencia de la vida bulliciosa de la ciudad conduce a desear una vida retirada del mundanal ruido. En su poesía, el tópico funciona para resolver la desilusión queleabrumaba ${ }^{8}$. D urante esta época, además, la Arcadia virgiliana se liga a la noción de Edad de 0 ro como formulaciones utópicas de tiempo y espacio. El Renacimiento también es pródigo en la configuración de una literatura de evasión urdida sobre el canon de la pastoral clásica (Bauza 1993, 207). D e particular interés es que estas formulaciones hayan trascendido el marco literario extendiéndose a otros géneros y moldes de expresión, como la plástica; y más aún, que hayan invadido otras esferas del pensamiento, como lo social y político, continuando vigentes aún hasta el presente.

Rodríguez Juliá, en su libro Campeche o los diablejos de la melancolía, lee en los trazos y la emblemática de la pintura de José Campeche, primer pintor puertorriqueño, del siglo XVIII, un posible relato pictórico en el que se representa un primer estadio de este gesto en Puerto Rico. En su comentario sobre el retrato del gobernador U stáriz advierte un contrapunto: a la derecha, el trazado utópico en el mapa de la ciudad se corresponde con el paisaje arcádico del cuadro del fondo. Según él, Campeche sugiere que el espacio perfecto de la ciudad trazada en el mapa utópico es el recuerdo ciudadano de la arcadia. A la izquierda el espacio del gabinete se abre y a través de una ventana se observa la

${ }^{7} D$ ámaso Alonso, comentando el tópico del lugar ameno en la "Egloga III" de Garcilaso, señala que "es un tópico tan viejo como el mundo, porque es una apetencia invariable en las invariables dimensiones del hombre: y $\mathrm{H}$ oracio pedía yacer "sub alta uel plátano uel hac / pinu" y pedía Fray Luis estar "a la sombra tendido", y lo ha pedido siempre el aspeado y asendereado ser humano, anteayer, y ayer, y hoy. jH oy, como nunca!" ("G arcilaso y los límites de la estilística," Elías L. Rivers, ed. La poesía de G arcilaso. Barcelona: A riel, 1981: 283-284).

${ }^{8} \mathrm{U}$ tilizamos la edición de sus poesías preparada por M anuel Durán y M ichael Atlee. La introducción del libro discute este aspecto de la poesía que mencionamos. Fray Luis de León, Poesías (M adrid: Cátedra, 1984). 
ciudad real. La ventana permite la entrada de la luz exterior y el rumor de la ciudad histórica, cual la historia reafirmándose en el aposento de la utopía. Esa ventana no sólo permite un encuentro con la ciudad histórica sino que también nos permite, según el escritor, un encuentro con nosotros mismos (21-24). Lo que ocurre y en el espacio público se atisba desde el espacio privado retratado. Tras la representación utópica como recuerdo y como proyecto persiste una presencia que el trazado intenta borrar, pero que sigue allí. Ese rumor de la ciudad como memoria a la quela versión histórica oficial en su trazado utópico insiste en no escuchar, constituye las voces de lo que Rodríguez Juliá llamará "las pesadillas de la historia". Frente a la representación utópica del pasado en las versiones oficiales, que como evocaciones tienden al ensueño como gesto evasor dela realidad histórica presente, Rodríguez Juliá propone lo que ha llamado las "pesadillas de la historia".

Entonces, un poco la pesadilla, un poco lo que es imaginación y ensoñación, se convierte en un hecho literario significativo para entender el mundo de la vigilia, para entender el mundo histórico (0 rtega 32).

La postura del autor se revela como crítica a la práctica excluyente de las versiones oficiales, tanto en el contenido temático como en la estética de éstas. En unas meditaciones sobre Puerto Rico y el C aribe, Rodríguez Juliá señala que los grandes escritores y artistas del Caribe coinciden en hablar de la "modorra" 0 tedium vitae característico de la condición colonial, en que el alma está como suspendida, indecisa entre una sociedad a medio hacer y la nostalgia de una tradición. Según el escritor, esta marginalidad crea un territorio de ensoñación o conduce al exilio. En su apreciación de la pintura de Francisco O ller, artista puertorriqueño formado en la escuela impresionista, observa que el cromatismo impresionista da paso paulatinamente a un realismo menos atento a los delicados cambios de luz sobre las formas y más ocupado en la formulación pictórica, casi emblemática, de los espacios y concreciones -flora y vivienda, bodegones y paisajes campestres- de la vida señorial fundada en la hacienda y sus memorias (513-514). Los espacios, que se perciben perfectos y apacibles son, según el autor, una especie de asidero; a través de ellos el pintor desarraigado recupera su país de origen. Esta apacibilidad y perfección que el escritor

${ }^{9}$ Refiriéndose a La noche oscura del niño Avilés, señala que: ... es irreverente con esa historia porque se niega a mirar el pasado desde el pasado. M i novela intenta un diálogo como significación para nosotros, para el presente. Ese diálogo, esa interlocución tiene que ser, por lo tanto, sincrónico y ucrónico, un espacio de congre gación para todas las voces y poses, actitudes y modas, ... "E dgardo Rodríguez Juliá: La historia bajo acecho" (Reproducido en: O rtega, 154-155) (El destacado es nuestro). 
advierte en la obra de Oller la observamos particularmente en las pinturas de las haciendas, en cuyas escenas de agreste quietud se comunica una interrelación casi orgánica entre la tierra y la estructura de la casa ${ }^{10}$. Las versiones del nacional ismo cultural ista, muy cercanas a las formulaciones pictóricas de 0 ller, se distinguen por lo que podríamos caracterizar - arriesgándonos a una simplificación-, como una práctica realista que atiende más a la sensación de realidad que a la realidad misma. Su carácter de ensoñación, propio de las formulaciones utópicas, corresponde a la experiencia que el personaje Baltasar M ontañez, en la cita de nuestro epígrafe, Ilama "delectación en presente". Las "pesadillas de la historia" serían entonces los aspectos de la realidad que las versiones históricas dejan fuera.

El ateneísta Alejandro Cadalso, en sus conferencias sobre La renuncia del héroe Baltasar, se propone examinar la figura de Baltasar M ontañez como "elocuente testimonio de nosotros mismos". Este enigmático héroe del siglo XVIII, según C adalso, tiene mucho que decir acerca de nuestra condición. Contraria a la práctica historiográfica tradicional, el objeto de la investigación está centrado en los aspectos más vel ados de la naturaleza humana. Cobra importancia la dimensión intrahistórica, las figuras de bajo relieve que, en cambio, tienen una gran profundidad humana, y que colaboran, tanto como otras, en la configuración de nuestra imagen. Baltasar M ontañez sería una de esas figuras: "Su lugar, su estancia histórica está entre la gran historia y la intrahistoria, entre la truculencia del hecho trascendente y el susurro de las vidas ignotas" (7-8).

A la experiencia del proceso modernizador y la voracidad del capital extranjero durante las primeras décadas del presente siglo se añade el surgimiento de otros sectores y escenarios social es que escapan a la arquitectura del relato letrado. Es cuando se propone entonces un programa de unidad y armonía social (Rodríguez-C astro 1993, 48 y ss.). Frente a la modernización democratizadora que habilita el acceso de la muchedumbre a la vida pública, la nación, a imagen de la Arcadia añorada por los letrados, debe recuperar la armonía. Para ello es necesario lograr la concordia, el cuerpo de la nación debe ser templado eliminando lo discorde. El papel central lo asumen los letrados y su quehacer adquiere una función formativa11. La literatura, y en particular la ensayística, pro-

\footnotetext{
${ }^{10}$ La muestra de la obra de 0 ller así como los textos críticos compilados en el catálogo de la exposición de 1983, celebrada en el M useo de Arte de Ponce, Puerto Rico, permiten una mejor apreciación de los comentarios del autor. Las observaciones de la curadora $\mathrm{H}$ aydee Venegas sobre las pinturas de las haciendas son de particular interés para la apreciación. Francisco Oller. U n realista del Impresionismo (M useo de Arte de Ponce, 1983).

${ }^{11} \mathrm{M}$ aría Elena Rodríguez-C astro ha examinado los dos niveles pragmáticos del programa letrado, que asume una labor tanto informativa como formativa. El proyecto, además de
} 
ceden dentro de ciertos preceptos ideológicos al seguir ciertas pautas establecidas por el nacionalismo cultural. D e este modo el quehacer cultural se corresponde con el pensamiento político en la actividad ordenadora eintegradora de todos los aspectos que según ellos definían la identidad. El proyecto asume al nivel de la cultura una proyección ético-estética. Se establecen ciertas normas que alcanzan a las esferas tanto sociales como culturales. La noción de identidad nacional postulada se basaba en la recuperación de un sistema de normas y valores tradicionales, entre los que se destacaron el hispanismo, el catolicismo, la pureza de la lengua y la necesidad de la jerarquización social (RodríguezCastro 1987-88, 63). Al ordenamiento de la nación le corresponde un ordenamiento de la producción cultural. La lengua en general y la literatura en particular serán unas de las preocupaciones de los intelectuales de la "Generación del 30". El uso correcto de la lengua se percibía como un gesto defensivo de la nacionalidad. Ecos de esta preceptiva ideológica se aprecian en las ideas de Pedro Salinas, el intelectual español que en su momento quizás más influencia ejerció en la enseñanza universitaria de la lengua. Su discurso pronunciado en ocasión de la colación de grados de la Universidad de Puerto Rico en 1944, Aprecio y defensa del lenguaje, compila las ideas centrales que respecto a la lengua compartían los treintistas. U na de las primeras ideas que desarrolla es preci samente la importancia de la relación lengua-nacionalidad, pues "está generalmente reconocido el valor de la lengua para el sentimiento de la nacionalidad" (22). I dentificando la lengua con el espíritu observa la necesidad de una política de la lengua, cuya finalidad es que "el ser humano, por medio de la cabal posesión de su lengua, logre la cabal posesión de su personalidad pensante y afectiva, su dignidad entera de individuo". Para que esta política funcione propone al gunas líneas de acción, entre las cual es destaca la aceptación de una norma lingüística. D entro de este punto destaca su admiración por el sentimiento del decoro del lenguaje en el campesino castellano, cuya sensibilidad para la calidad del lenguaje es, según Salinas, superior a la del obrero fabril de la ciudad (70-73). Rasgos de esta ideología cultural estarán presentes en la escritura eufemística de René $M$ arqués, escritor que representará la crisis del nacionalismo cultural ${ }^{12}$. D e este modo se practica en la esfera cultural un saneamiento acorde con el

informar, de construir el relato de la nación, persigue formar a los intelectuales y a la masa en pro del proyecto propuesto. En esta empresa, los letrados asumirán, como puntualiza la crítica, el papel de guías o maestros. Vea específicamente la segunda parte de su tesis (ver bibliografía).

2 Una discusión sobre la relación entre el nacionalismo cultural y la lengua en la producción literaria puertorriqueña puede ser apreciada en el libro de Juan Gelpí Literatura v paternalismo en Puerto Rico (San Juan: Universidad de Puerto Rico, 1993). 
saneamiento social| ${ }^{13}$. La literatura, siguiendo el sentido de búsqueda, implícito en el tópico de la Arcadia como recuperación de la vieja concordia, intenta templar la lengua y la expresión, así como la nación, eliminando todo lo discorde. En Puerto Rico se observa lo que M ichael $D$ ash señala sobre la literatura del Caribe. Según el crítico, el ansia por las virtudes de claridad, una sintaxis patricia y una dicción elegante es compartida por muchos de los primeros escritores queinsistían en imponer una estética descarnada sobre el misterio y la deformidad de la realidad (487).

Respecto a la descarnalidad dela lengua, Edgardo Rodríguez Juliá menciona, remitiendo al Inca G arcilaso de la Vega, que la recuperación de la memoria comienza con el replanteo del cuerpo. En su obra, el cuerpo constituye una forma de autoconciencia materializada. Las formas, las partes del cuerpo se transforman en entonaciones como la voz a la palabra. En La noche oscura del niño Avilés la recurrencia a las imágenes de la erotomanía, del frenesí erótico apare cen como recuperación del cuerpo casi borrado por la explotación esclavista (0 rtega, 156). Las alusiones a la voluptuosidad del cuerpo femenino en sus novel as y en su crónica "U na noche con I ris C hacón", además de transgredir las convenciones de la literatura anterior, en su exaltación del decoro y de lo sublime, transgreden también una de las imágenes poéticas de extracción romántica que caracterizó a los discursos del nacional ismo. Muchos escritores coincidían en la utilización de la figura femenina como al egoría de la tierra. En la imaginación poética de estos escritores, la figura femenina mantenía una correspondencia con la armonía y templanza del paisaje. La mujer, amante y madre, era parte integrante del paisaje idílico evocado. En la mitificación del Caribe en términos del cuerpo femenino, desde el siglo XIX, se establece una relación entre el cuerpo dispuesto y tendido en oposición al cuerpo volátil y evasivo (D ash, 484). En la literatura actual la proliferación de las imágenes violentas, así como la erotización de la palabra responden a la represión tanto verbal como carnal que se ejerció durante mucho tiempo. Esta naturaleza dual de la represión en el Caribe es el foco de atención de Caribbean D iscourse de Edouard Glissant, quien subraya la relación inextricable entre la auto-afirmación verbal y física. En la crónica de R odríguez J uliá, la vedette puertorriqueña I ris C hacón

13 "Entonces y desde el territorio cultural se puede renacer. Esa es la tarea, una misión ética que, expresada en un lenguaje médico, curativo, se traduce en un acto regenerativo '... inyectar sanidad, sangre nueva, optimismo y alegría en el cuerpo desgastado de la sociedad" (M.E. Rodríguez-C astro 1993: 42). Aquí se da cita una de las principales propuestas del pensamiento utópico de Platón, para quien las costumbres de un Estado dependen del nive moral de los individuos, por lo que reclama cuatro virtudes necesarias: sabiduría, valor, templanza y justicia (Cf. Servier, 27). 
transforma su cuerpo en topografía identificándolo con distintos lugares turísticos del país. Su voluptuosidad contrarrestará la imagen docilitada del paisaje; la identificación con la "M adreTierra" implica un modo de celebración del cuerpo como espacio de ensoñación necesario. Sus alusiones a la topografía corporal, sus gestos e insinuaciones, rompen con el decoro, y la imagen de la mujer pasiva y recatada queda destruida (142).

A la armonía pretendida en la nación se correspondía la armonía de la cultura y de sus manifestaciones. Esto dio paso a una exclusión de lo discordante en las versiones oficiales de la historia y la identidad cultural. Las versiones oficiales integraban en sus definiciones culturales sólo aquellos elementos que armonizaran entre sí. Frente a estas versiones, en la obra de Edgardo Rodríguez Juliá ocurre algo muy distinto. Las novelas y las crónicas permiten la entrada a lo disonante, la confluencia de géneros, voces, poses, la carnalidad verbal, que se corresponde con la sensualidad visual y la voluptuosidad corporal. Sus obras, frente a la U topía de la nación y la cultura el aborada por generaciones anteriores, constituyen una $\mathrm{H}$ eterotopía similar a la que el mismo autor describe en dos de sus crónicas. En "Para llegar a Isla Verde" se detiene en la descripción de la ornamentación de un auto, el "Volky" de Roberto. En este auto se integran diversos signos al usivos a la cultura. Según Rodríguez Juliá, el artista entiende el espacio plástico como un lugar de coincidencias imposibles. En la obra hay un esfuerzo por fundar otro modo de utopía, un espacio perfecto donde todo cabe, donde las voces crean, por encima de su soledad, la armonía de la cultura. No obstante, como espacio de congregación de signos diversos y hasta opuestos, la obra expresa un arte donde "el más" se concibe no como exceso sino como complejidad (El cruce, 70-85). Al comentar la pintura "La pelea" en su ensayo "EI jardín violado y recuperado: la pintura de Rafael Ferrer en Las Terrenas", el autor observa cómo por la figura que presenta el torneo, ubicada a la derecha "en el lugar donde tantas soledades coinciden", parece pasar la interlocución del espectador, de las luchadoras y los testigos de la escena. La obra genera una interlocución múltipley a la vez muda, en la que todas las posibilidades semióticas se abren y cierran súbitamente. D e acuerdo a Rodríguez Juliá estamos frente a ese laberinto de signos que es la heterotopía según Foucault (El cruce, 148-150).

$\mathrm{M}$ ichel Foucault distingue las heterotopías de las utopías, primero por el efecto que logran: las utopías, por no tener lugar real y desarrollarse en un lugar maravilloso, consuelan; las heterotopías, al minar el lenguaje, enmarañar los nombres y arruinar la sintaxis - no sólo la que organiza las frases sino la que mantiene juntas a las palabras y las cosas-, inquietan. Por ello, según Foucault, las utopías permiten las fábulas y los discursos: se encuentran en el filo recto del lenguaje. Q ue es decir en lo bien dispuesto, en el orden. Las heterotopías en cambio "secan el propósito, detienen las palabras en sí mismas, desafían, desde 
su raíz, toda posibilidad de gramática; desatan los mitos y envuelven en esterilidad el lirismo de las frases" (3). Las heterotopías al minar el orden dan paso a lo incongruente, al desorden que hace centellear los fragmentos de un gran número de posibles órdenes.

Las obras de Edgardo Rodríguez Juliá, como heterotopías, se ofrecen como espacio de congregación de órdenes distintos. La proliferación temática y verbal logra una apertura semiótica del texto. El texto, particularmente el novelesco, como elaboración utópica y ucrónica, remite a hechos tanto reales como ficticios, a lo comprobable y a lo imaginario. $\mathrm{H}$ ay una congregación de nombres, lugares y hechos difíciles de catalogar. Algunos aun sabidos improbables suscitan asociaciones con hechos o lugares reales, potenciándose así lo posible. Las novelas y crónicas de Rodríguez Juliá se abren como espacio de interlocución; la multiplicidad de cronistas en sus novelas - al gunos, autores de versiones diferentes de un mismo relato-, así como el exceso de rostros y voces en sus crónicas, que muchas veces dificultan la tiranía del narrador-cronista, aunado a la incomprensión por éste, logran una fisura en el espacio textual por donde se permite la entrada del lector como interlocutor. Esta interlocución no es sólo entre las voces textuales y el lector, sino entre los planos mismos en que están situados éstos: el pasado y el presente; la ficción y la realidad; la historia y la intrahistoria; lo observado y lo imaginario. Respecto a este aspecto el mismo autor ha mencionado cómo La noche oscura intenta un diálogo con el pasado como significación para el presente. Una interlocución sincrónica y ucrónica, un espacio de congregación para todas las voces y poses, actitudes y modos, "que explique la actual agresividad y resentimiento de un joven lumpen y mulato de Villa Palmeras desde las coordenadas de una revuelta de esclavos en el dieciocho" (O rtega, 154-155).

A la templanza pretendida de las formulaciones utópicas, que como una de las virtudes necesarias implica una templanza en la expresión, se opone el cuerpo destemplado como imagen heterotópica, espacio sincrético que remite a la realidad social y cultural. La imagen de la vedette Iris Chacón aparece como espacio de coincidencias imposibles: lo sublime con la voluptuosidad corporal, la ternura con la agresividad gestual y verbal, el objeto deseado con el venerado. Estas "coincidencias imposibles" acusan la ruptura con la escritura excluyente; aquí todo cabe. El texto se abre y deja entrar una diversidad de voces y rostros queacusan un exceso de presencia quees en sí la cultura puertorriqueña; y va al escenario que esta diversidad habita, la ciudad.

La intromisión de lo real como elemento discordante en las ensoñaciones patricias ya se observaba en la trayectoria de la obra del pintor O ller. Rodríguez Juliá señala cómo de la apacible utopía señorial se pasa a una heterotopía donde las distintas etnias sólo pueden convivir en disonancia ("Puerto Rico y el Cari- 
be", 514-515). En la pintura "El velorio", de Oller, coinciden en un mismo espacio las distintas etnias de la cultura puertorriqueña. Esta obra se revela como la concreción de la invasión de la ciudad real al espacio utópico que Rodríguez J uliá advertía en su interpretación del retrato de U stáriz pintado por Campeche.

\section{BIBLIO G RAFIA}

Bauzá, H ugo Francisco. 1993. El imaginario clásico: Edad de oro, utopía y arcadia. Santiago de Compostela: Universidade, Servicio de Publicación e Intercambio Científico.

Dash, M ichael. 1989. "D esmembrar y remembrar: la poética del cuerpo en la literatura caribeña". La Torre 3.2: 483-491.

D íaz Q uiñones, Arcadio. 1984. "Recordando el futuro imaginario: la escriturahistórica en la década del treinta". Sin N ombre 14: 16-35.

Fernández Valledor, Roberto. 1993. I dentidad nacional y sociedad en la ensayística cubana y puertorriqueña (1920-1940). San Juan: Centro de Estudios Avanzados de Puerto Rico y el Caribe.

Foucault, M ichel. 1985. Laspalabrasy lascosas. U na arqueología delas ciencias humanas. M adrid: Siglo Veintiuno.

Glissant, Edouard. 1989. Caribbean D iscourse. Selected Essays. Charlottesville: University Press of Virginia.

Gonzál ez, José Luis. 1978. El país de cuatro pisos y otros ensayos. Río Piedras: H uracán.

Gonzál ez Pérez, Aníbal. 1986. "U na al egoría de la cultura puertorriqueña: La noche oscura del niño Avilés, de Edgardo Rodríguez Juliá". Revista Iberoamericana 52. 135-136: 583-590.

1992. "I mágenes de la conquista y la colonia en la novelística hispanoamericana contemporánea: N otas para una interpretación". Revista de Estudios H ispánicos, 431-448.

O rtega, Julio. 1991. Reapropiaciones (Cultura y nueva escritura en Puerto Rico). Río Piedras: Universidad de Puerto Rico.

Pedreira, Antonio S. 1970. O bras de Antonio S. Pedreira. Ed. Concha M eléndez. San Juan: Instituto de Cultura Puertorriqueña.

Rodríguez-C astro, M aría Elena. 1987-88. "Tradición y modernidad: El intelectual puertorriqueño ante la década del treinta". Boletín del Centro de Investigaciones Históricas 3: 45-65.

. 1988. La escritura de lo nacional y los intelectuales puertorriqueños Tesis doctoral. Princeton U niversity.

. 1993. "Las casas del porvenir: N ación y narración en el ensayo puertorriqueño". Revista I beroamericana 59. 162-163: 33-54.

Rodríguez Juliá, Edgardo. 1974. La renuncia del héroe Baltasar. Río Piedras: Cultural. 
1984. La noche oscura del niño Avilés Río Piedras: Huracán.

1985. "Tradición y utopía en el barroco caribeño". Calibán 1.2, pp. 2.

1986. Campeche o los diablej os de la melancolía. San Juan: Instituto de cultura Puertorriqueña.

1986. Una noche con Iris Chacón. San Juan: Antillana.

1989. El cruce de la bahía de Guánica. Río Piedras: H uracán.

. 1989. "Puerto Rico y el Caribe: H istoria de una marginalidad". La Torre 3.11: $513-529$.

Rosario, Rubén del. 1985. Selección de ensayos lingüísticos. M adrid: Partenón.

Salinas, Pedro. 1944. A precio y defensa del Ienguaje. Río Piedras: U niversidad de Puerto Rico.

Servier, Jean. 1969. Historia de la utopía. Venezuela: M onte Avila. 